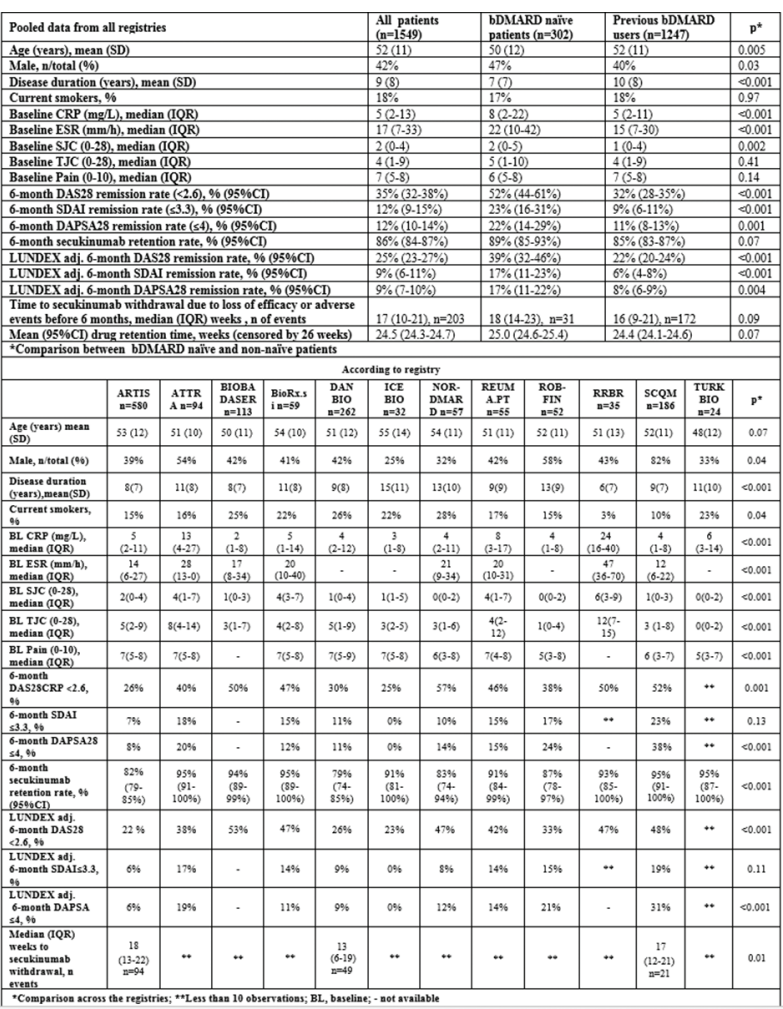

declared, Björn Gudbjornsson: None declared, Sema Yilmaz: None declared. Florenzo lannone Consultant for: $F$ lannone has received consultancy fees and/or speaker honoraria from Pfizer, AbbVie, MSD, BMS, Novartis, Lilly, UCB outside this work, Speakers bureau: F lannone has received consultancy fees and/or speaker honoraria from Pfizer, AbbVie, MSD, BMS, Novartis, Lilly, UCB outside this work, Ulf Lindström: None declared, Anne Gitte Loft: None declared, Burkhard Moeller Consultant for: Swissmedic Human Medicines Expert Committee Member (regulatory agency), Carlos Sánchez-Piedra: None declared, Karel Pavelka: None declared, Matija Tomsic: None declared, Eirik kristianslund: None declared, Helena Santos: None declared, Anna-Mari Hokkanen: None declared, Ruxandra lonescu: None declared, Thorvardur Jon Love Consultant for: Received reimbursment from Celgene for speaking about guidelines for the treatment of psoriatic arthritis, Yavuz Pehlivan: None declared, Marco Sebastiani: None declared, Gareth T. Jones Grant/ research support from: Have received research grants (not current) from Abbvie and Pfizer.

Have received research grants (not current) from the British Society for Rheumatology, who received the funds from Abbive, Pfizer and UCB. Have received research grant (current) from the British Society for Rheumatology, who received the funds from Celgene., Irene van der HorstBruinsma Grant/research support from: MSD, Pfizer, AbbVie, Consultant for: Abbvie, UCB, MSD, Novartis, Speakers bureau: BMS, AbbVie, Pfizer, MSD, Lise Hyldstrup: None declared, Niels Steen Krogh: None declared, Merete L. Hetland Grant/research support from: BMS, MSD, AbbVie, Roche, Novartis, Biogen, Pfizer, Consultant for: Eli Lilly, Speakers bureau: Orion Pharma, Biogen, Pfizer, CellTrion, Merck, Samsung Bioepis, Mikkel stergaard Grant/research support from: Abbvie, Celgene, Centocor, Merck, Novartis, Consultant for: Abbvie, BMS, Boehringer-Ingelheim, Celgene, Eli Lilly, Hospira, Janssen, Merck, Novartis, Novo, Orion, Pfizer, Regeneron, Roche, and UCB, Speakers bureau: Abbvie, BMS, Boehringer-Ingelheim, Celgene, Eli Lilly, Hospira, Janssen, Merck, Novartis, Novo, Orion, Pfizer, Regeneron, Roche, and UCB

DOI: 10.1136/annrheumdis-2019-eular.2233

\section{SAT0392 IMPLEMENTING THE PSORIATIC ARTHRITIS DISEASE ACTIVITY SCORE (PASDAS) IN ROUTINE CLINICAL PRACTICE: (IM)POSSIBLE?}

Michelle Mulder ${ }^{1}$, Alfons den Broeder ${ }^{1,2}$, Berbke van Ginneken ${ }^{1}$, Johanna Vriezekolk ${ }^{1}$, Elien Mahler ${ }^{1}$, Frank van den Hoogen ${ }^{1,2}$, Mark Wenink ${ }^{1}$. ${ }^{1}$ Sint Maartenskliniek, Rheumatology, Ubbergen, Netherlands; ${ }^{2}$ Radboud University Medical Center, Rheumatic Diseases, Nijmegen, Netherlands

Background: Psoriatic arthritis (PsA) is a heterogeneous disease, with involvement of at least five health domains: peripheral joint disease, enthesitis, dactylitis, axial involvement, and skin and nail psoriasis. Because of the heterogeneity of the disease, assessment of disease activity is challenging. One of the many single or composite outcome measures that has been developed is the Psoriatic Arthritis Disease Activity Score (PASDAS). The PASDAS is a comprehensive measure that takes arthritis (66/68 joint score), dactylitis, enthesitis, CRP, physician disease activity VAS score and patient-reported outcomes into account ${ }^{1}$. Furthermore, it is a continuous outcome measure in contrast to the Minimal Disease Activity criteria (MDA), facilitating the longitudinal follow-up of disease activity. The PASDAS also has better parametric distribution and discriminative capacity compared to other outcome measures such as the Disease Activity for PSoriatic Arthritis score (DAPSA). However, feasibility of PASDAS use in routine clinical care has been questioned due to its complexity. It requires a CRP and filled-out SF36 form at time of assessment, does not include a formal skin assessment, is difficult to calculate and is time consuming for both patient and physician.

Objectives: To implement PASDAS measurements and skin assessments in routine clinical care for all 1300 PsA patients treated at our centre. Methods: The implementation consisted of the following stages: 1) assessment of patients' acceptability of measurement burden; 2) implementation of mathematical calculations of the PASDAS in our electronic health record; 3) PASDAS and skin assessment training of rheumatology nurses and rheumatologists; and 4) (logistic) adjustments to the outpatient visit.

Results: Our patient partners preferred comprehensive clinical assessment of skin and joints above a limited assessment (such as the DAS28-CRP), although the latter would be less time consuming. For this reason, and to comply with international guidelines, we decided to also add assessment of skin disease, by using the Body Surface Area (BSA) and Physician Global Assessment score (PGA). Furthermore, research demonstrated that for the PASDAS calculation the physical component score (PCS) of the SF36 could be substituted by the SF12$\mathrm{PCS}^{2}$. As the SF12 is more concise, minimizing patient burden, we chose to implement the SF12 instead of the SF36. The SF12-PCS, together with the other separate component scores and corresponding mathematical calculation of the PASDAS, was implemented in our electronic health record. Lastly, we set-up a three phase consultation that consists of laboratory tests and consultation with a rheumatology nurse who performs the physical measurements before each visit with the physician.

Conclusion: Standardized and routine measurement of the PASDAS and skin involvement at each outpatient visit of all our PSA patients before consultation with the treating rheumatologist was successfully implemented, underscoring the feasibility of this approach. In addition to improving clinical care, routine outcome measurements can be used for a variety of clinical studies.

\section{REFERENCES}

[1] Helliwell, P.S., et al., The development of candidate composite disease activity and responder indices for psoriatic arthritis (GRACE Project). Ann of the Rheum Dis. 2013 Jun;72(6):986-91.

[2] Helliwell, P.S, et al., Modification of the Psoriatic Arthritis Disease Activity Score (PASDAS). Ann Rheum Dis. 2018 Mar;77(3):467-468.

Disclosure of Interests: Michelle Mulder: None declared, Alfons den Broeder: None declared, Berbke van Ginneken: None declared, Johanna Vriezekolk: None declared, Elien Mahler: None declared, Frank van den Hoogen: None declared, Mark Wenink Consultant for: abbvie DOI: 10.1136/annrheumdis-2019-eular.2758 